\title{
Design of an Open Practice Teaching Platform for Microcomputer Based on "the Internet Plus"
}

\author{
Lijun Hao ${ }^{a^{*}}$, Yan Wang ${ }^{b}$,Si Boyu ${ }^{c}$ and Yutong Zha ${ }^{d}$ \\ College of Medical Instrument \\ Shanghai University of Medicine \&Healthy \\ Shanghai, China \\ ahaolj@sumhs.edu.cn, bwangy_194@sumhs.edu.cn, csiby@sumhs.edu.cn, dzhayt@sumhs.edu.cn \\ *Lijun Hao
}

Keywords: Internet plus, OpenStack, Virtual, Practical teaching platform.

\begin{abstract}
In the paper, a practical teaching platform for the course of principle and application of microcomputer is developed based on the "Internet plus". The course of principle and application of microcomputer is a professional course that is equal to the theory and practice. But most of experimental site cannot meet the needs of learning in real time because of its management and the slow equipment update for most of schools. By combing with "the Internet plus", a practical teaching platform is designed here. On the platform, a cloud management is used to realize virtualization distribution and management based on OpenStack. Thus, the utilization of resources can be effectively improved. Different virtual machines are designed in the cloud server according to the number of experiments. Then, the students can apply an account to obtain a short time or along term virtual machine and visit the platform and do practice on it at any time through virtual accounts. This mode will break through the limitation of time and space. And the real opening of the laboratory will be realized. And it is generally applicable to most of the higher school.
\end{abstract}

\section{Introduction}

"The universal application of Internet plus" has injected new impetus to education. And it promote education to the network, digital, intelligent and national development [1]. With the help of these technologies, it can realize the open space in time and space for teaching and learning [2].

For the course of principle and application of microcomputer, both theory and practice are emphasized. Especially the practical ability is particularly important for applied undergraduate colleges. Therefore, the opening of laboratories is a very important step in the reform of experimental teaching in colleges and universities in the new era [3]. However, in the traditional concept, the opening of the laboratory is the opening of the physical space.

This paper will introduce a microcomputer practice teaching platform that built on the cloud environment. Then the practice cannot be limited to venues and time. By the platform, the students can visit the experiment development environment at any time. It is helpful to facilitate the students' autonomous learning. And the laboratory has realized opened up really at low cost.

\section{The Present Teaching Situation of the Course of Microcomputer Principle}

\subsection{Features of Curriculum}

The course of principle and application of microcomputer is one of the important basic courses of Biomedical Engineering in our school. It has a total class hour of 64 hours, and the number of practical classes is 16 hours. The course teaching content covers the $\mathrm{x} 86$ microcomputer system, the x86 assembly language, the memory, the input and output interface, the bus and so on. It refers contents included the software development and the hardware design. For the software development 
part, a low-level programming language - assembly language is adopted. In addition, the programming mode is based on the hardware structure of the microprocessor, which also leads to the abstract and obscure development of the microcomputer software. Therefore, it is very common among students that the "compilation will not be compiled".

In the limited teaching time, we found the teaching effect is not ideal as we expected. Many students lost their interest and give up the course when they cannot keep up with the class due to the lack of effective teaching platform.

The purpose of practical courses is to improve the students' practical ability and deepen their understanding of theoretical knowledge. But unfortunately, the limited time for practice teaching make it is impossible to spend much time on the practice teaching. Moreover, the aging of laboratory equipment is also a common problem faced by many colleges and universities. Therefore, in practice teaching, in order to facilitate the organization and management, our experiment mainly focuses on the verifying content. The purpose of this design is to ensure that most students can complete the experiment within the prescribed time and achieve the goal of teaching conservatively. But the drawback is that students are passive, resulting in difficulty in programming [4].

For this reason, we would better increase the design experiment to enable students to complete the experiment by thinking and designing. This kind of design may encourage students to think. Maybe it is useful to encourage the students not to fear programming, thus promoting their learning into a virtuous circle. Furthermore, a completely different effect will be achieved. But we also have to consider these two problems. First, the level of students is different. Second, the completion time cannot be well controlled. The laboratory is a common resource, and it cannot guarantee the continuous use of the same students for a long time.

\section{2 "Internet plus education" as an opportunity to explore new teaching mode}

In the limited class time constraints, "Internet plus education" concept for us to explore the new teaching mode of open thinking. Combining with online and offline, we can make full use of the resources of online courses. And this will promote the development of teaching more effectively. A new teaching mode will be applied.

In the new mode, first, we can make the traditional classroom as the leading role. The role of the teachers in the class is to inspire the students' interest in learning. Second, with the guidance of problems, the students are urged to use the network resources for exploration and study. By various ways and intensive study after class, the students can master knowledge more actively. Finally, we are back to the classroom. The emphasis thing in the classroom at this time is to solve problems and to answer different doubts. This new teaching model will be more effective

In order to complement each other online and offline, it is necessary to develop supporting network resources. In the paper, we try to construct an open practice teaching platform for the course of principle and application of microcomputer based on the cloud environment.

\section{Design of Computer Simulation Teaching Practice Platform Based on the "Internet Plus"}

The platform is based on cloud environment development, using virtual machine technology, composed of management control module and cloud desktop module.

In the system, the OpenStack management control module will carry out specific resource allocation and calculation when the platform is being applied. The student first apply the virtual machine through the UI port, and then visits the virtual machine through the cloud desktop. At the personal PC side, the student can perform programing exercises just by remote access to open the virtual machine. Based on the "Internet plus", a practical teaching platform of microcomputer is designed in the paper. The platform is based on cloud environment development, using virtual machine technology, composed of management control module and cloud desktop module. 


\subsection{The management and application of virtual machine}

Based on OpenStack, the platform is managed by virtual machine, including server virtualization and desktop virtualization. Server virtualization technology can realize the separation of server hardware and application system. A physical server is virtual to multiple virtual servers by virtualization of the server. So many different operating systems can be run at the same time. Each virtual server can dynamically allocate the resources according to the actual needs, so that the utilization of the server is greatly improved.

Desktop virtualization is the use of virtualization technology and distributed technology, the client's operating system, application and user data are concentrated on the server of the data center, and the user operating environment is separated from the actual operating environment of the system. Thus the centralized monitoring and management of all terminal desktops can be realized, and the management efficiency is improved [5]. After desktop virtualization, the student can access their desktop system at anytime and anywhere.

As shown in Fig.1, the manager uniform manages and designs the virtual machine templates which correspond to different experimental projects. The number of machine templates is depended on the number of the experiments. Different virtual machine template mirrors correspond to different experimental projects. According to the need, a virtual machine template can be derived to duplicate multiple virtual machines. The student then can apply for a temporary or long-term virtual machine through the windows remote desktop connection. Meanwhile, he or she can select the virtual machine with the appropriate mirroring and virtual machine features.

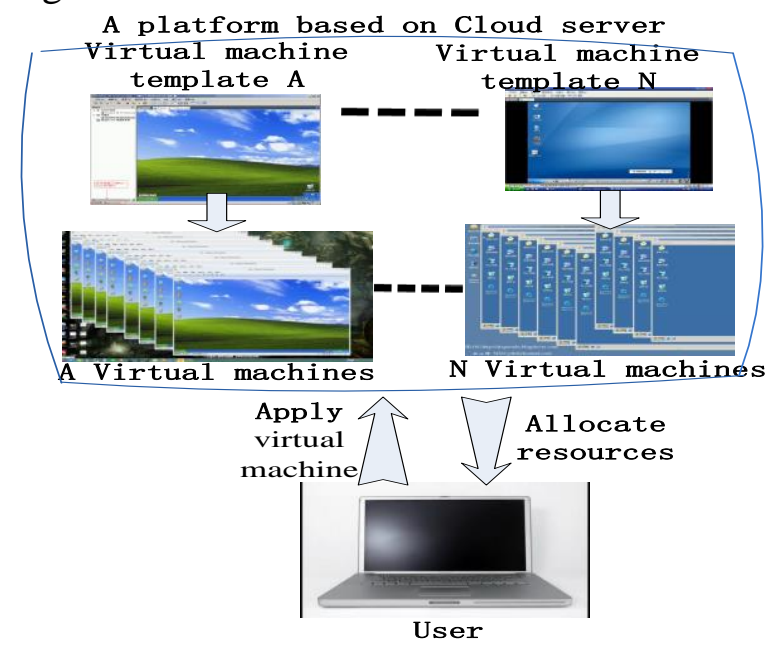

Fig. 1. The architecture of the platform based on virtual template

\subsection{Application of the platform in the practical teaching of Microcomputer}

At the beginning of each semester, the cloud platform manager will allocate accounts for specific teachers and students. They are the users of the platform. As shown in Fig.2, the teacher's authority is relatively high. They can regularly publish a semester's practical teaching projects and publish the results of the experiment for each student. Furthermore, they can also stipulate the completion time of the project and check all the students' experimental completion. Meanwhile, the student can check the teacher's practical project guidance book and complete the practice project within the specified time [5].

In order to increase interest and challenge, except for some basic or difficult experiments, we can also set up a number of customs clearance experiments. The purpose is to make full use of the students' interest, stimulate their learning motivation, and increase the fun of learning, let the students indulge in the "game", and complete the experiment in the "game". 


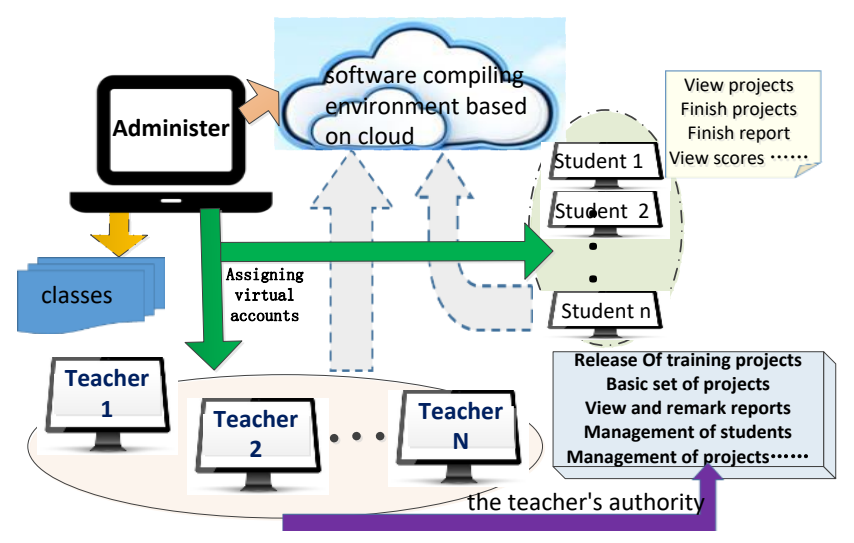

Fig. 2. The functional design of a practical teaching platform for microcomputer

\section{Summary}

The course of principle and application of microcomputer is a basic and professional course for many engineering majors. Therefore, the curriculum arrangement cannot really meet the needs of teaching. In this paper, the difficulties encountered in the teaching of Principle and Application of Microcomputer are discussed. With the guidance of the "Internet plus education" concept, a new virtual teaching platform is constructed based on the cloud environment. On this platform, the students have their own independent virtual desktop system on the server by applying remote hosting special virtual desktop. Although the students share applications with other users, they are isolated from each other. It can ensure security and distribute the resources on demand when sharing resources. Thus it will improve the utilization of resources. It is more convenient for students to learn and practice. And it is also more convenient for teachers to manage. The greatest advantage of the platform is that it can break the traditional time and space restrictions. With the help of the platform, practical learning, just like theoretical learning, can be done anytime and anywhere.

\section{Acknowledgement}

The authors gratefully acknowledge the support of Educational Reform Project of Shanghai University of Medicine \& Healthy under Grant No. B1-0200-18-309127.

\section{References}

[1] Y. Zhang, Analysis of the "Internet plus education" concept and mode, China Academic Journal Electronic Publishing House, pp.70-73, Feb.2016.

[2] J.G. Zhang, L.T. Luo, Construction of digital teaching resources platform based on Cloud Computing, Modern Educational Technology, vol.21, pp.100-102, 2011.

[3] Y. Cui ,Q. Li , Exploration of Open Quality Demonstration Classroom of Microcomputer Principle Course, Education Teaching Forum,vol.6,pp.212-213,2017.

[4] Q. L. Ma, Y. Le, D. Hu, J. Wang, X. F. Hu, Teaching reform and practice of Microcomputer Principle Course for Biomedical Engineering Specialty, Education Teaching Forum,No.50,pp.87-88,Dec.2015.

[5] L. J. Hao, Y. Wang. Construction of Virtualization Software Programming Training Cloud Platform Based on OpenStack, 4th International Conference on Education Reform and Management Innovation,pp.235-239,Feb 2017. 